\title{
Race-Specific Adult-Plant Resistance in Winter Wheat to Stripe Rust and Characterization of Pathogen Virulence Patterns
}

\author{
Eugene A. Milus (retired), David E. Moon, Kevin D. Lee, and R. Esten Mason
}

First, second, and third authors: Department of Plant Pathology, University of Arkansas, Fayetteville 72701; and fourth author: Department of Crop, Soil and Environmental Sciences, University of Arkansas, Fayetteville 72701.

Current address of K. D. Lee: DuPont Crop Protection, Lawrence, KS.

Accepted for publication 24 February 2015.

\begin{abstract}
Milus, E. A., Moon, D. E., Lee, K. D., and Mason, R. E. 2015. Racespecific adult-plant resistance in winter wheat to stripe rust and characterization of pathogen virulence patterns. Phytopathology 105: 1114-1122.

Stripe rust, caused by Puccinia striiformis f. sp. tritici, is an important disease of wheat in the Great Plains and southeastern United States. Growing resistant cultivars is the preferred means for managing stripe rust, but new virulence in the pathogen population overcomes some of the resistance. The objectives of this study were to characterize the stripe rust resistance in contemporary soft and hard red winter wheat cultivars, to characterize the virulence of $P$. striiformis f. sp. tritici isolates based on the resistances found in the cultivars, and to determine wheat breeders' perceptions on the importance and methods for achieving stripe rust resistance. Seedlings of cultivars were susceptible to recent isolates,

were resistant or susceptible depending on the isolate, indicating they had race-specific adult-plant resistance. Using isolates collected from 1990 to 2013, six major virulence patterns were identified on adult plants of twelve cultivars that were selected as adult-plant differentials. Race-specific adult-plant resistance appears to be the only effective type of resistance protecting wheat from stripe rust in eastern United States. Among wheat breeders, the importance of incorporating stripe rust resistance into cultivars ranged from high to low depending on the frequency of epidemics in their region, and most sources of stripe rust resistance were either unknown or already overcome by virulence in the pathogen population. Breeders with a high priority for stripe rust resistance made most of their selections based on adult-plant reactions in the field, whereas breeders with a low priority for resistance based selections on molecular markers for major all-stage resistance genes.
\end{abstract} indicating they lacked effective all-stage resistance. However, adult-plants
Since a new strain of the pathogen emerged in 2000 (Markell and Milus 2008), stripe rust, caused by Puccinia striiformis f. sp. tritici, has been the most important foliar disease of soft red winter wheat (SRWW) in southeastern United States and hard red winter wheat (HRWW) in the Great Plains (Basnet et al. 2014, Sthapit et al. 2012). The new strain had new virulence on all-stage resistance genes $\operatorname{Yr} 8$ and $\operatorname{Yr} 9$ (Chen et al. 2002) and was more aggressive and adapted to warmer temperatures than the old strain (Milus et al. 2006, 2009). Growing resistant cultivars is the most efficient means for managing stripe rust (Chen 2005). The two major types of resistance to stripe rust are all-stage and adult-plant. All-stage resistance (also known as seedling resistance) provides a high level of resistance from the seedling stage through maturity but is usually overcome by new races of the pathogen (Chen 2005). With adultplant resistance (APR), seedlings are susceptible and plants become resistant as they mature (Vanderplank 1982). Different types of APR have been described. Cromey (1992), Ma and Singh (1996) and Park and Rees (1989) found two types of APR. One type expressed as early as tillering stage, was associated with a hypersensitive infection type (IT) on flag leaves, and provided a high level of resistance in the field. Another type developed later, was associated with intermediate ITs, and provided slow-rusting in the field. Hovmøller (2007) found that APR was common in European wheat cultivars with levels of effectiveness ranging from low to high. Resistance genes $\operatorname{Yrl1} 1,12,13$, and 14 conferred a high level of APR with a hypersensitive IT to some isolates but were

Corresponding author: E. A. Milus; E-mail address: gmilus@uark.edu overcome by other isolates (McIntosh et al. 1995). Qayoum and Line (1985) described high-temperature adult-plant resistance (HTAP) that requires a combination of maturity and warm temperatures for expression. HTAP resistance (Chen 2005) and APR conferred by Yrl8 (Ma and Singh, 1996) were considered to be durable because they remained effective for a long time when deployed across a large area with high disease pressure.

Sthapit et al. (2012) evaluated 18 SRWW lines that were susceptible as seedlings to races PST-3 (representative of the old strain) and PST78 (representative of the new strain) plus 26R61 that had all-stage resistance to PST-3 (due to $Y r 9$ ) for APR to these races at low (10 to $18^{\circ} \mathrm{C}$ ) and high $\left(12\right.$ to $28^{\circ} \mathrm{C}$ ) gradually changing temperature regimes. Nine lines had race-specific APR to PST-78 but were susceptible to PST-3, nine lines had APR to both races, and 26R61 had APR to PST78. Furthermore, only one line seemed to express a higher level of APR at the high temperature regime than at the low temperature regime, indicating that the APR found in these lines was different from HTAP resistance. These results indicated that APR was ubiquitous among the lines evaluated and that the APR in half of the lines was race-specific.

According to Zadoks (1961), German scientists in the 1930s were the first to discover APR and race-specific APR to stripe rust. In the 1940s, Manners (1950) conducted experiments to determine the types of stripe rust resistance present in wheat cultivars grown in Great Britain. He found that (i) cultivars resistant to particular isolates at the seedling stage (i.e., cultivars had all-stage resistance) were always resistant to those isolates at the adult stage, (ii) cultivars not fully susceptible to particular isolates at the seedling stage were likely to have useful levels of resistance to those isolates at the adult stage, and (iii) cultivars fully susceptible to particular isolates at the seedling stage could be either resistant or susceptible at the adult stage depending on the isolate. 
Zadoks (1961) investigated resistance to wheat stripe rust and physiologic specialization of $P$. striiformis f. sp. tritici in Europe during the $1950 \mathrm{~s}$. He found that mature plant resistance (i.e., APR) was more important for managing stripe rust than overall resistance (i.e., all-stage resistance) and that "field races" based on the reaction of adult plants in the field explained major epidemics better than "greenhouse races" based on seedling reactions in the greenhouse. He found that several greenhouse races could be split into two or more field races and that some greenhouse races could be combined into one field race.

Da Silva (1958) discussed the need for better integration of race identification of cereal rust fungi with efforts to breed resistant cultivars. The major problem was that race identification based on a standard set of differentials identified many races that were not important to breeding programs but did not identify subraces capable of attacking contemporary cultivars. This problem was addressed by adding supplemental differentials particular to different regions that contained the resistances used within a region. From a practical breeding standpoint, the supplemental differentials needed to be continuously updated as regional cultivars changed over time, and important races in the field were most likely to be differentiated on the supplemental differentials rather than the standard differentials.

In the 1970s, Priestley and Doodson (1976) determined that it was critical to describe races of $P$. striiformis $\mathrm{f}$. sp. tritici in the United Kingdom based on adult-plant reactions because all widely grown wheat cultivars were susceptible to contemporary isolates at the seedling stage. They planted replicate tussocks (hill plots) of commercially important cultivars in each of several polyethylene tunnels, inoculated plants in each tunnel with a different isolate, and were able to identify five races based on adult-plant reactions. Priestley et al. (1984) proposed a dynamic system utilizing a set of cultivars representing the range of effective resistances and contemporary isolates representing the range of virulence found in the field for efficiently evaluating currently important cultivars for both all-stage and adult-plant resistances to stripe rust. This system with some modifications is still being used in the United Kingdom. In 2012 for example, Hubbard and Bayles (2013) tested five isolates in individual inoculated field nurseries consisting of replicated plots of 51 cultivars. The isolates were obtained from cultivars that had been rated as highly resistant in the field but later developed low levels of stripe rust. All of the isolates were virulent on seedlings of the cultivar from which they were obtained. Stripe rust intensity was evaluated eight times between flag leaf emergence and early milk stages. The mean intensity was used as a measure of virulence on adult plants, allowing gradual transitions (Zadoks 1961) or progressive increases (McIntosh et al. 1995) in virulence to be quantified and confirming virulence on five cultivars that had been rated as highly resistant in the field. In the United States, there appears to have been no reports of race-specific APR to stripe rust before 2002 (Line 2002), and races of $P$. striiformis f. sp. tritici are identified on seedlings of 20 differential lines (Chen et al. 2002, Wan and Chen 2012) with no known attempts to identify races based on adult-plant reactions.

The objectives of this study were to characterize the stripe rust resistance in contemporary SRWW and HRWW cultivars, to characterize the virulence of $P$. striiformis f. sp. tritici isolates based on the resistances found in the cultivars, and to determine wheat breeders' perceptions on the importance and methods for achieving stripe rust resistance.

\section{MATERIALS AND METHODS}

Characterization of resistance. The 96 entries in the 2013 Arkansas Wheat Cultivar Performance Test (Mason et al. 2013) were evaluated for resistance to stripe rust at four field locations where stripe rust occurred naturally. Resistance was evaluated by estimating the percentage of total leaf area with sporulating stripe rust lesions at soft dough stage in four replicate plots (approximately $1.5 \mathrm{~m}$ wide $\times$
$6 \mathrm{~m}$ long) of each cultivar in a randomized complete block design at each location. Sixteen of these entries were considered commonly grown SRWW cultivars and also were evaluated for all-stage resistance to eight single-lesion $P$. striiformis f. sp. tritici isolates collected from five locations in Arkansas during 2013. All-stage resistance was evaluated on seedlings at a 5 to $18^{\circ} \mathrm{C}$ gradually changing temperature regime as described previously (Sthapit et al. 2012), except that inoculum (10 mg spores per gram talc) was applied with a powder blower (Sunrise Medical HHG Inc., Somerset, PA) and ITs were recorded separately on first and second leaves.

Eight HRWW lines and seven SRWW lines containing $Y r 17$ that were susceptible at the seedling stage to races PSTV-37 from Arkansas and PST-127 from Washington (provided by X. Chen) and that had a range of resistance levels at two field locations with PSTv-37 (Milus et al. 2015) were evaluated for APR under controlled conditions compared with a susceptible check. The lines were vernalized in a growth chamber and grown in a greenhouse as described by Sthapit et al. (2012). To synchronize heading among plants of the 16 lines, the first plants to have emerging flag leaves were moved to a growth chamber programmed to gradually change from 10 to $15^{\circ} \mathrm{C}$ with a 14 -h photoperiod to slow development. Plants in the chamber were returned to the greenhouse at least $48 \mathrm{~h}$ before inoculation. At early heading stage when expression of APR should be high (Sthapit et al. 2012), a flag leaf on three plants of each line was inoculated with race PSTv-37, and a flag leaf on another three plants of each line was inoculated with race PST-127. Inoculations were done using a powder blower to apply spores mixed with talc (30 $\mathrm{mg} \mathrm{g}^{-1}$ ). After approximately $24 \mathrm{~h}$ in a dew chamber at $12^{\circ} \mathrm{C}$, plants were kept in a growth chamber programmed to gradually change from 10 to $18^{\circ} \mathrm{C}$ with a 14-h photoperiod. Light intensity in the 400 to $700 \mathrm{~nm}$ range was 430 to $470 \mu \mathrm{mol} \mathrm{m}^{-2} \mathrm{~s}^{-1}$ at the flag leaf level as measured using an Apogee Quantum meter, model 200 (Apogee Instruments, Inc., Logan, UT). The IT and disease intensity on flag leaves were recorded at 14, 17, and 20 dai as described previously (Sthapit et al. 2012). The experimental design was a splitplot with two repetitions of the experiment as the whole plot and a factorial of two pathogen isolates and 16 wheat lines with three replications as the split-plot. Area under disease progress curve (AUDPC) was calculated based on the three estimates of disease intensity and analyzed using Proc MIXED, SAS version 9.1.3 (SAS Institute, Cary, NC). Race and line were considered fixed effects, and experimental run and replication were considered random effects. Because AUDPC values could not be calculated for two experimental units due to premature plant death, least-squares means were compared using a protected least significant difference (LSD) at $P=0.05$ based on the number of observations for each mean.

To compare the levels of APR among wheat lines based on the AUDPC values under controlled conditions as described above with levels of APR observed in the field, relative AUDPC values for race PSTv-37 were compared with relative stripe rust intensity values for the lines in five location-years in which PSTv-37 was the predominant race (Milus et al. 2015). Relative values were calculated by dividing the AUDPC and intensity values of each line by the corresponding AUDPC and intensity values for the susceptible check, Croplan Genetics 514W.

Reactions of $\boldsymbol{P}$. striiformis f. sp. tritici isolates on adult-plant differentials. A susceptible check (Croplan Genetics 514W), seven SRWW cultivars (Progeny 166, Arcadia, Mason, AGS 2035, LA 821, 26R61, and VA07W-415), and four HRWW cultivars (Jagger, Everest, TAM 111, and Pete) were selected as adult-plant differentials based on reactions in the field that suggested they might differentiate isolates at adult-plant stages. Seven of these cultivars are known to have all-stage $Y r$ genes that are effective against certain isolates. 26R61 has $\operatorname{Yr} 9$ (Sthapit et al. 2012), LA 821, Jagger, and VA07W-415 have $\operatorname{Yr} 17$ (Milus et al. YR17), TAM 111 has QYr.tam-2BL (Basnet et al. 2014), and AGS 2015 has Yr9 (J. Johnson, personal communication). The remaining cultivars are not suspected of having any all-stage $Y r$ genes. The APR gene $Y r R 61$ is 
present in 26R61 (Hao et al. 2011) and AGS 2035 (J. Johnson, personal communication). Single-lesion isolates were selected to represent isolates from Arkansas in 2013 and the range of adultplant virulence found in tests with a preliminary set of 10 adult-plant differentials. Isolates were stored at $-80^{\circ} \mathrm{C}$ and grown on seedlings of 'Florida 302' for at least two generations as described previously (Sthapit et al. 2012) before being used in experiments. Seedlings and adult plants were grown and vernalized as described above. Differentials were inoculated at the two-leaf seedling stage to determine the level of all-stage resistance on first and second leaves and at boot stage to determine the level of APR on flag leaves. Urediniospores were diluted with talc $\left(10 \mathrm{mg} \mathrm{g}^{-1}\right)$ and applied with a powder blower. Dew chamber and growth chamber conditions were as described above. Two replicates of the differentials were inoculated in each seedling or adult-plant experiment, and each isolate was tested in at least two experiments at each growth stage. Ratings for IT and disease intensity at 18 to 21 dai were as described above. Reactions with ITs $\leq 3$ were considered resistant. Reactions were considered intermediate for ITs 4 to 6 or for higher ITs with intensities less than half that of the susceptible check. Reactions with ITs $\geq 7$ and intensities similar to the susceptible check were considered susceptible. Isolates used in this study have been deposited in collections managed by X. Chen and M. Hovmøller.

Breeders' perceptions of stripe rust resistance and how to achieve it. A survey was e-mailed to all known public and private SRWW and HRWW breeders in the United States. The questions were as follows: (i) What is your priority for incorporating stripe rust resistance into your cultivars - high, moderate, or low? (ii) What percentage of your selection effort for stripe rust resistance is based on seedling inoculations, adult plants in the field, and molecular markers? (iii) What percentage of your sources of stripe rust resistance are specific genes or markers, specific cultivars or lines, and unknown sources?

\section{RESULTS}

Characterization of resistance. The 16 commonly grown SRWW cultivars had high ITs similar to the susceptible check on both first and second seedling leaves after inoculation with each of the eight isolates from 2013 (Table 1). However, all cultivars except Progeny 185 had low stripe rust intensities at soft dough stage across the four field locations. Of the 96 entries in the 2013 Arkansas Wheat Cultivar Performance Test that were evaluated for resistance in the field, the number of entries with stripe rust intensities not significantly greater than 0 (one-tailed LSD test at $P=0.025$ ) were 92, 94, 75, and 81 at Keiser, Kibler, Newport, and Rohwer, respectively (data not shown), indicating that most of the entries had a high level of resistance to isolates that were prevalent in 2013.

Statistical analysis of AUDPC on flag leaves of SRWW and HRWW lines with $\operatorname{Yr} 17$ under controlled conditions showed that there was a significant $(P<0.0001)$ race-line interaction. Comparison of the race-line interaction means (Table 2) indicated that this interaction was due to significantly higher AUDPC values with race PSTV-37 than race PST-127 on eight of the 16 lines used in the experiment. The other eight lines had similar AUDPC values with both races. Although Jagger and LA01139D-56-1-C had significantly lower AUDPC values than the susceptible check (Croplan Genetics 514W) when inoculated with PSTv-37, these lines had AUDPC values similar to the susceptible check when inoculated with PST-127. HV9W05-1125, NE05426, NE06545, and TAM401 had low AUDPC values with both races. Differences in IT among lines inoculated with the two races (Table 2) generally agreed with the differences described above for AUDPC. However, AGS2060 gave mixed results in that it had high ITs to both races in run 1 and low ITs to both races in run 2 .

Characterization of virulence patterns on seedlings and adult plants of the APR differentials. Adult-plant virulence pattern (APVP) 1 is represented by isolates AR90-01 and AR97-01 of the old $P$. striiformis f. sp. tritici strain (Table 3). Croplan Genetics 514W (susceptible check), Progeny 166, Arcadia, Mason, and Pete had high ITs on all leaves and high intensities on flag leaves. AGS 2035, LA 821, 26R61, VA07W-415, Jagger, and TAM 111 had low or predominantly low ITs on both seedling leaves and no signs or symptoms on flag leaves. Everest had intermediate to high and high ITs on the first and second seedling leaves and high intensities with intermediate to high ITs on flag leaves.

APVP 2 is represented by isolates AR00-05 and AR03-33 of the new P. striiformis f. sp. tritici strain (Table 4). Croplan Genetics $514 \mathrm{~W}$ (susceptible check) was the only line that had high ITs on all leaves and high intensities on flag leaves. Progeny 166, Arcadia, Mason, and 26R61 had mostly high ITs on both seedling leaves but low intensities and ITs on flag leaves. AGS 2035, LA 821, Jagger,

TABLE 1. Stripe rust infection type (IT) on first and second leaves of seedlings inoculated with eight isolates ${ }^{\mathrm{a}}$ of Puccinia striiformis f. sp. tritici from Arkansas in 2013 and stripe rust intensity at soft dough stage in the field at four locations in Arkansas during 2013 for 16 commonly grown cultivars of soft red winter wheat

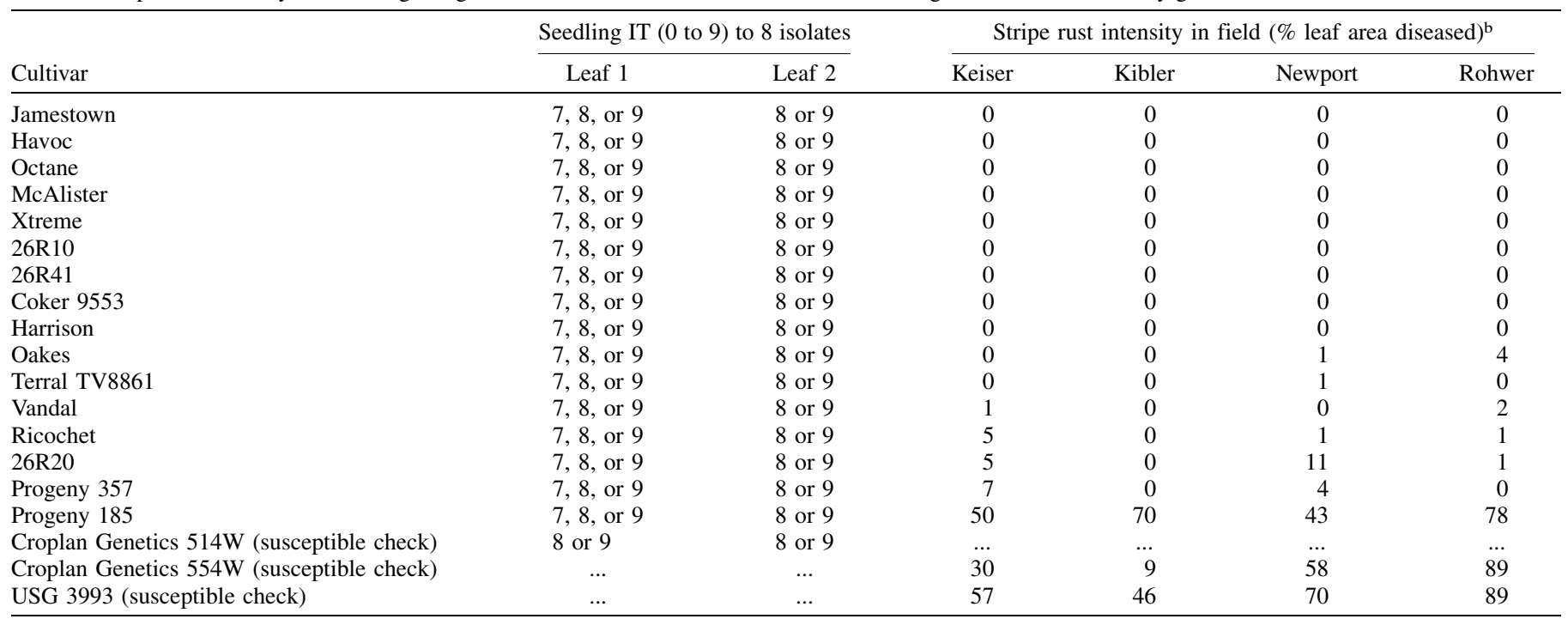

a AR13-01 from Lonoke; AR13-06 from North Little Rock; AR13-07, AR13-09, AR13-10 from Rohwer; AR13-12, AR13-14 from Newport, and AR13-15 from Kibler.

b Mean across four replicates of the Arkansas Wheat Cultivar Performance Test at each location in 2013. 
Everest, TAM 111, and Pete had low or predominantly low ITs on first seedling leaves, intermediate or high ITs on second seedling leaves, and low intensities and ITs on flag leaves, except for Pete that had intermediate to high ITs on flag leaves. VA07W-415 had higher ITs and intensity with AR03-33 than with AR00-05. APVP 3 is represented by isolates AR10-04 and AR 12-19 (Table 5) and was similar to APVP 2 except for higher ITs and severities on LA 821, VA07W-415, and Jagger that have Yr17.

APVP 4 is represented by isolate AR12-25 (Table 6). Both seedling leaves of all lines had mostly high ITs. On flag leaves, intensities and ITs were high except on Mason that had a low intensity and IT, Jagger that had an intermediate intensity and IT, and AGS 2035 that had an intermediate intensity.

APVP 5 is represented by AR13-06 and AR13-10 (Table 7) and four additional isolates from 2013 (data not shown). Both seedling leaves of all lines had high ITs. On flag leaves, intensities and ITs were high except on Arcadia and Mason that had low intensities and ITs, Everest that had low intensities and intermediate ITs, Jagger and VA07W-415 that had intermediate intensities and intermediate to high ITs, and AGS 2035 that had intermediate intensities and high ITs.

APVP 6 is represented by the type isolate of race PST-127 (Table 8). Both seedling leaves of all lines had high ITs. On flag leaves, intensities and ITs were high except on Mason and VA07W415 that had low intensities and ITs, Arcadia, LA 821, Everest, and TAM 111 that had high intensities and intermediate ITs, and AGS 2035 that had an intermediate intensity and intermediate to high ITs.

The reactions of the six APVPs on flag leaves of the 12 differentials are summarized in Figure 1. Based on these reactions, all of the APR was race-specific.

Breeders' perceptions of stripe rust resistance and how to achieve it. Ten SRWW and seven HRWW breeders responded to the survey, and their responses are summarized in Table 9. SRWW breeders were about evenly distributed for their priority for incorporating stripe rust resistance into their cultivars, whereas most HRWW breeders considered it a high priority. Regardless of wheat market class, most selection for stripe rust resistance was based on evaluating adult plants in the field. All but one breeder

TABLE 2. Area under the disease progress curve (AUDPC) averaged across two runs of the experiment and infection type (IT) on flag leaves of 16 wheat lines in Yr17 inoculated at heading stage with isolate AR10-04 (race PSTv-37a) and the type isolate of race PST-127b (both virulent on Yr9 and 17) of Puccinia striiformis f. sp. tritici and incubated at a 10 to $18^{\circ} \mathrm{C}$ gradually changing temperature regime with a 14 -h photoperiod

\begin{tabular}{|c|c|c|c|c|c|c|}
\hline \multirow[b]{3}{*}{ Line } & \multirow{2}{*}{\multicolumn{2}{|c|}{$\mathrm{AUDPC}^{\mathrm{c}}$}} & \multicolumn{4}{|c|}{ IT (0 to 9$)$} \\
\hline & & & \multicolumn{2}{|c|}{ Run 1} & \multicolumn{2}{|c|}{ Run 2} \\
\hline & AR10-04 & PST-127 & AR10-04 & PST-127 & AR10-04 & PST-127 \\
\hline Croplan Genetics 514W & 578 & 471 & 9 & 8 & 9 & 8 \\
\hline HV9W03-1596R & $520 * \mathrm{~d}$ & 227 & 7 & $2-5$ & 6 & $2-4$ \\
\hline VA07W-415 & $510 *$ & 239 & 9 & $2-5$ & 9 & $2-4$ \\
\hline VA06HRW-108 & $493 *$ & 207 & 9 & $2-5$ & 6 & $2-5$ \\
\hline LA 821 & $463 *$ & 155 & 9 & $2-7$ & 9 & $2-4$ \\
\hline HV9W04-1594R & $458 *$ & 118 & 9 & $2-5$ & 9 & $2-4$ \\
\hline SS8641 & $413 *$ & 88 & 7 & 3 & 7 & $2-4$ \\
\hline Jagger & 408 & 450 & 8 & 9 & 9 & 7 \\
\hline VA08MAS-412 & $377 *$ & 146 & 9 & $2-5$ & 8 & $2-4$ \\
\hline LA01139D-56-1-C & 341 & 416 & 8 & $2-4$ & 7 & $2-4$ \\
\hline AGS 2026 & 306 & 205 & 4 & 4 & 3 & $2-4$ \\
\hline AGS 2060 & 301 & 329 & 8 & 7 & $2-4$ & $2-4$ \\
\hline HV9W05-1125 & $215^{*}$ & 69 & 6 & 4 & 7 & $2-3$ \\
\hline NE05426 & 203 & 136 & 7 & 4 & 8 & $2-4$ \\
\hline NE06545 & 169 & 101 & 3 & $3-6$ & 2 & $2-4$ \\
\hline TAM401 & 122 & 41 & 4 & 3 & 4 & $2-4$ \\
\hline
\end{tabular}

a Since 2010, races were determined on a new set of differentials described by Chen (2014).

b Before 2010, races were determined on a set of differentials described by Chen et al. (2002).

${ }^{c}$ Least significant difference (LSD) $(P=0.05)=117$ for comparing any pair of AUDPC values except as follows where there were missing values. For comparing NE05426 inoculated with AR10-04 or VA06HRW-108 inoculated with PST-127 to any other mean, the LSD $(P=0.05)=123$.

$\mathrm{d} *$ Indicates a significantly higher value for AR10-04 than PST-127.

TABLE 3. Infection type (IT, 0 to 9 scale) on first and second leaves of seedlings and stripe rust intensity (percentage of leaf area diseased) and IT on flag leaves of differential wheat lines inoculated with Puccinia striiformis f. sp. tritici isolates AR90-01 and AR97-01 (both race PST-3 ${ }^{\text {a) }}$ that have adult-plant virulence pattern 1

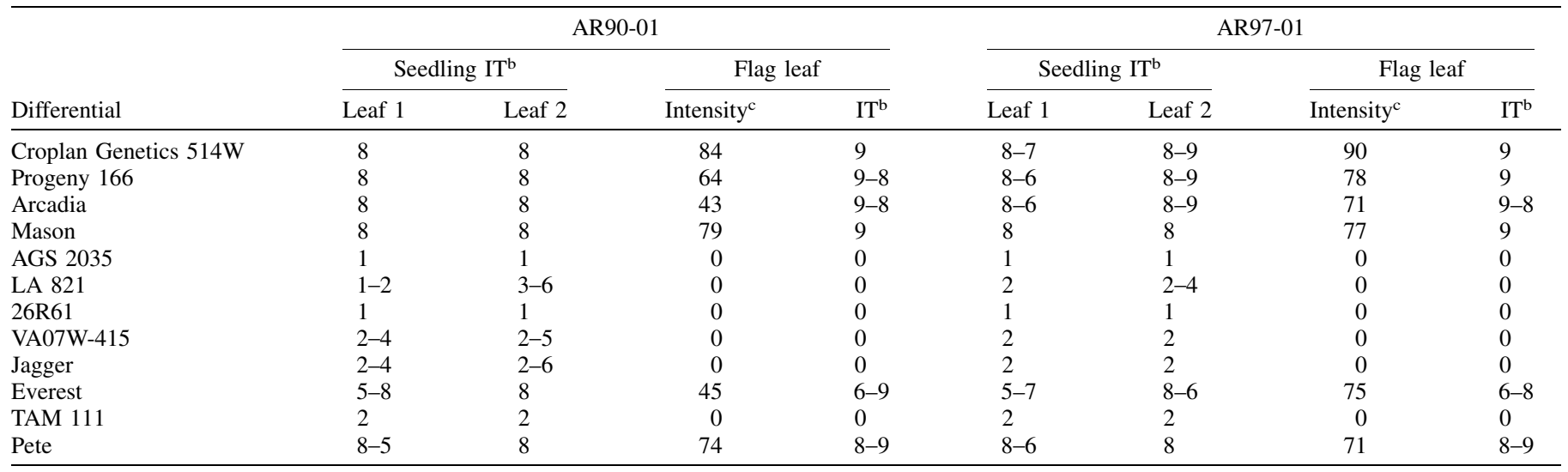

a Race designation based on the U.S. standard set of differentials before 2010 (Chen et al. 2002).

b A dash (-) indicates a range of ITs with the predominant IT listed first across two repetitions of the experiment with two replications each.

c Averaged across two repetitions of the experiment with two replications each. 
reported using molecular markers for stripe rust resistance, and two breeders relied completely on markers for incorporating stripe rust resistance. One SRWW and four HRWW breeders used seedling inoculations for a small portion of their selection effort. Regardless of market class, breeders considered most of their sources of stripe rust resistance as unknown. Among the specific $Y r$ genes and sources being used, $\operatorname{Yr} 17$ (seven responses) and 26R61 (four responses) were the most frequently listed. Among the all-stage genes that are effective in eastern United States, $\operatorname{Yr} 5,10$, and 15 were the most frequently used by breeders who utilize molecular markers (two responses for each).

\section{DISCUSSION}

The results of this study indicate that there was no effective allstage resistance to isolates of $P$. striiformis $\mathrm{f}$. $\mathrm{sp}$. tritici collected in 2013 among the 16 commonly grown SRWW cultivars or the 12 APR differential lines selected for this study. Likewise, there was no effective all-stage resistance to PSTv-37 or PST-127 among the eight HRWW and seven SRWW lines with Yrl7. Given these results, race identification on seedling differentials cannot explain differences in virulence that are important to wheat growers or breeders in eastern United States. As discussed by McIntosh (2010) and da Silva (1958), virulence data are most useful when they accurately predict what will happen in farmers' fields. To be most useful, differentials should include the resistances used in regional cultivars and advanced breeding lines.

APR was identified in all of the HRWW and SRWW cultivars and lines evaluated except for the susceptible check (Croplan Genetics 514W) and Progeny 185. This is similar to the situation in the United Kingdom in the early 1970 s that made assaying $P$. striiformis f. sp. tritici virulence on adult-plant differentials a common practice (Priestley and Doodson 1976). Furthermore, the APR in all the APR differential lines and in 10 of 15 lines with $\mathrm{Yr} 17$ was shown to be race-specific. This agrees with previous reports of race-specific APR to stripe rust in winter wheat cultivars from eastern United States (Sthapit et al. 2012, Markell et al. 2009), Europe (Hovmøller 2007, Hubbard and Bayles 2013, Zadoks 1961) and with the conclusion of Danial et al. (1995) that resistances conferring a hypersensitive reactions are likely race-specific. However, these results are contrary to those from western United States where racespecific APR has never been reported and all APR has been classified as HTAP that is effective against all races (Line 2002, Chen 2007).

Based on the major patterns of stripe rust intensity and IT on flag leaves of the APR differentials, isolates were classified into one of

TABLE 4. Infection type (IT, 0 to 9 scale) on first and second leaves of seedlings and stripe rust intensity (percentage of leaf area diseased) and IT on flag leaves of differential wheat lines inoculated with Puccinia striiformis f. sp. tritici isolates AR00-05 (race PST-78 ${ }^{\mathrm{a}}$ ) and AR03-33 (race PST-100 ${ }^{\mathrm{a}}$ ) that have adult-plant virulence pattern 2

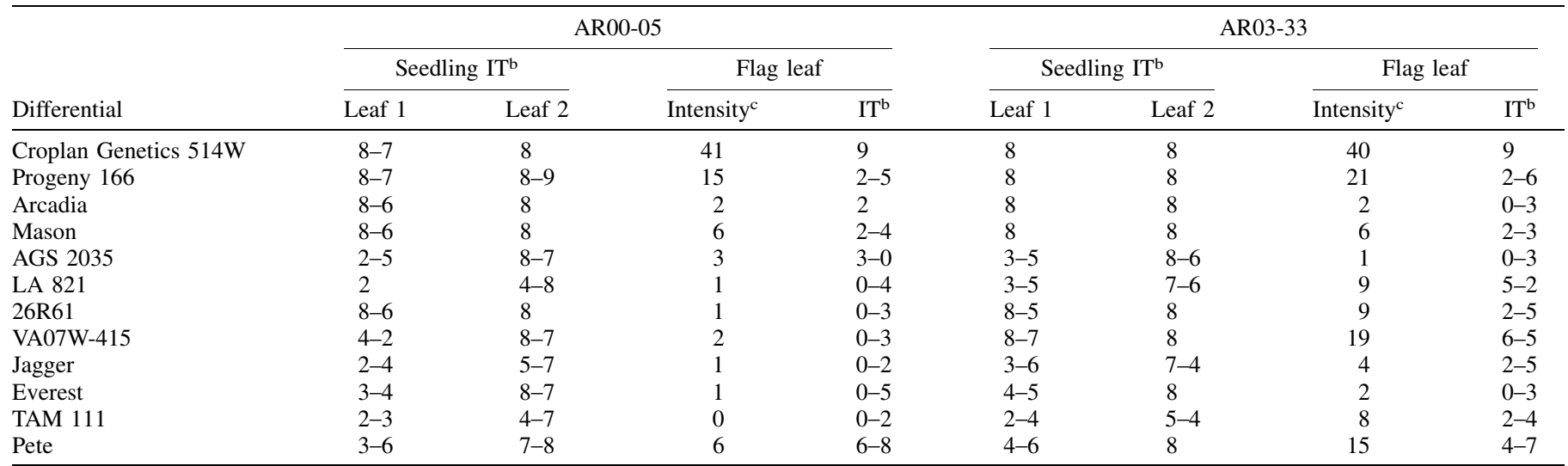

a Race designation based on the U.S. standard set of differentials before 2010 (Chen et al. 2002).

b A dash (-) indicates a range of ITs with the predominant IT listed first across two repetitions of the experiment with two replications each.

c Averaged across two repetitions of the experiment with two replications each.

TABLE 5. Infection type (IT, 0 to 9 scale) on first and second leaves of seedlings and stripe rust intensity (percentage of leaf area diseased) and IT on flag leaves of differential wheat lines inoculated with Puccinia striiformis f. sp. tritici isolates AR10-04 (race PSTv-37a) and AR12-19 (race PSTv-34 ${ }^{\mathrm{a}}$ ) that have adult-plant virulence pattern 3

\begin{tabular}{|c|c|c|c|c|c|c|c|c|}
\hline \multirow[b]{3}{*}{ Differential } & \multicolumn{4}{|c|}{ AR10-04 } & \multicolumn{4}{|c|}{ AR12-19 } \\
\hline & \multicolumn{2}{|c|}{ Seedling $\mathrm{IT}^{\mathrm{b}}$} & \multicolumn{2}{|c|}{ Flag leaf } & \multicolumn{2}{|c|}{ Seedling IT $^{\mathrm{b}}$} & \multicolumn{2}{|c|}{ Flag leaf } \\
\hline & Leaf 1 & Leaf 2 & Intensity $^{\mathrm{c}}$ & $\mathrm{IT}^{\mathrm{b}}$ & Leaf 1 & Leaf 2 & Intensity $^{\mathrm{c}}$ & $\mathrm{IT}^{\mathrm{b}}$ \\
\hline Progeny 166 & 8 & 8 & 6 & $2-3$ & 8 & 8 & 21 & $2-5$ \\
\hline Arcadia & $5-8$ & 8 & 8 & $0-4$ & 8 & 8 & 1 & $1-2$ \\
\hline Mason & $8-6$ & 8 & 6 & $0-2$ & 8 & 8 & 6 & $2-3$ \\
\hline AGS 2035 & $2-6$ & $7-5$ & 6 & $5-6$ & $2-4$ & $7-8$ & 10 & $5-7$ \\
\hline VA07W-415 & $8-7$ & $8-9$ & 57 & $9-8$ & $8-7$ & $8-9$ & 82 & 9 \\
\hline Jagger & $6-2$ & $8-7$ & 25 & $6-8$ & $8-7$ & $8-9$ & 64 & $9-8$ \\
\hline Everest & 8 & 8 & 2 & $0-2$ & 8 & 8 & 6 & $2-3$ \\
\hline TAM 111 & $2-5$ & $6-8$ & 2 & 1 & $3-2$ & $7-8$ & 6 & $1-2$ \\
\hline Pete & $7-3$ & $8-6$ & 29 & $6-7$ & $8-5$ & 8 & 50 & $7-5$ \\
\hline
\end{tabular}

${ }^{a}$ Race designation based on the new U.S. standard set of differentials since 2010 (Chen 2014).

b A dash (-) indicates a range of ITs with the predominant IT listed first across two repetitions of the experiment with two replications each.

${ }^{c}$ Averaged across two repetitions of the experiment with two replications each. 
six APVPs. This term was chosen rather than "adult-plant race" because races are described on a standard set of differentials (Roelfs 1984, Zadoks 1961), and there was no intention of proposing the differentials used in this study as a standard set. On the contrary, adult-plant differentials need to be flexible and should be chosen from among important contemporary cultivars and advanced breeding lines that are susceptible to contemporary isolates at the seedling stage but have been resistant in the field as described by da Silva (1958) and Zadoks (1961) and put into practice in the United Kingdom (Priestley et al. 1984, Hubbard and Bayles 2013).

The expression of stripe rust resistance is often different under different environmental conditions (Boyd 2005, Zadoks 1961). The results of our study were based on a monocyclic infection of flag leaves under high inoculum density and arbitrary environmental conditions in a growth chamber that may be favorable for the expression of some resistance genes but unfavorable for the expression of others. Relative AUDPC values (i.e., relative to the susceptible check) for the 15 wheat lines inoculated with race PSTv-37 under controlled conditions at a gradually changing 10 to $18^{\circ} \mathrm{C}$ temperature regime ranged from 0.21 to 0.90 and averaged

TABLE 6. Infection type (IT, 0 to 9 scale) on first and second leaves of seedlings and stripe rust intensity (percentage of leaf area diseased) and IT on flag leaves of differential wheat lines inoculated with Puccinia striiformis $\mathrm{f}$. sp. tritici isolate AR12-25 (PSTv-39) that has adult-plant virulence pattern 4

\begin{tabular}{|c|c|c|c|c|}
\hline \multirow[b]{3}{*}{ Differential } & \multicolumn{4}{|c|}{ AR12-25 } \\
\hline & \multicolumn{2}{|c|}{ Seedling $\mathrm{IT}^{\mathrm{b}}$} & \multicolumn{2}{|c|}{ Flag leaf } \\
\hline & Leaf 1 & Leaf 2 & Intensity $^{c}$ & $\mathrm{IT}^{\mathrm{b}}$ \\
\hline Croplan Genetics 514 & 8 & $8-9$ & 80 & 9 \\
\hline Progeny 166 & 8 & $8-9$ & 75 & 9 \\
\hline Arcadia & 8 & 8 & 75 & $8-7$ \\
\hline Mason & 8 & $8-9$ & 6 & 1 \\
\hline AGS 2035 & 8 & $8-9$ & 35 & $9-8$ \\
\hline LA 821 & 8 & $8-9$ & 65 & $9-8$ \\
\hline 26R61 & 8 & $8-9$ & 70 & 9 \\
\hline VA07W-415 & $8-5$ & $8-9$ & 56 & $7-8$ \\
\hline Jagger & $5-8$ & $8-6$ & 35 & $6-3$ \\
\hline Everest & 8 & 8 & 70 & $8-9$ \\
\hline TAM 111 & 8 & $8-9$ & 80 & 9 \\
\hline Pete & 8 & 8 & 72 & $9-8$ \\
\hline
\end{tabular}

${ }^{a}$ Race designation based on the new U.S. standard set of differentials since 2010 (Chen 2014).

${ }^{\mathrm{b}}$ A dash (-) indicates a range of ITs with the predominant IT listed first across two repetitions of the experiment with two replications each.

c Averaged across two repetitions of the experiment with two replications each.
0.61 (calculated from data in Table 2). Relative stripe rust intensities for the same 15 lines at soft dough stage in the field averaged 0.08 , $0.13,0.15,0.18$, and 0.34 in five location-years in which PSTv-37 was the predominant race (calculated from data in Milus et al. 2015). AUDPC values under controlled conditions underestimated the resistance in the field except for line VA07W-415 at Fayetteville in 2011. The 10 to $18^{\circ} \mathrm{C}$ temperature regime is representative of temperatures in the field during the early spring in Arkansas and is favorable for stripe rust development, whereas warmer temperatures that occur later in the growing season are more favorable for the expression of some resistances and less favorable for stripe rust development (Zadoks 1961). Quantification of APR levels in field nurseries based on polycyclic infection cycles under natural conditions and with multiple evaluations during the epidemic as done in the United Kingdom (Hubbard and Bayles 2013) and Denmark (Hovmøller 2007) is likely the most accurate method for evaluating APR of wheat lines and adult-plant virulence of $P$. striiformis f. $\mathrm{sp}$. tritici isolates.

TABLE 8. Infection type (IT, 0 to 9 scale) on first and second leaves of seedlings and stripe rust intensity (percentage of leaf area diseased) and IT on flag leaves of differential wheat lines inoculated with the type isolate of Puccinia striiformis f. sp. tritici race PST-127 a that has adult-plant virulence pattern 6

\begin{tabular}{|c|c|c|c|c|}
\hline \multirow[b]{3}{*}{ Differential } & \multicolumn{4}{|c|}{ PST-127 } \\
\hline & \multicolumn{2}{|c|}{ Seedling IT (0 to 9$)^{\mathrm{b}}$} & \multicolumn{2}{|c|}{ Flag leaf } \\
\hline & Leaf 1 & Leaf 2 & Intensity $^{\mathrm{c}}(\%)$ & $\mathrm{IT}^{\mathrm{b}}$ \\
\hline Croplan Genetics 514 & 8 & 8 & 95 & 9 \\
\hline Progeny 166 & 8 & 8 & 90 & 9 \\
\hline Arcadia & 8 & 8 & 77 & $3-6$ \\
\hline Mason & 8 & $8-9$ & 7 & 1 \\
\hline AGS 2035 & 8 & 8 & 31 & $6-8$ \\
\hline LA 821 & 8 & 8 & 55 & $2-5$ \\
\hline 26R61 & 8 & 8 & 75 & 9 \\
\hline VA07W-415 & 8 & 8 & 21 & $1-3$ \\
\hline Jagger & 8 & 8 & 54 & $9-8$ \\
\hline Everest & 8 & 8 & 57 & $6-5$ \\
\hline TAM 111 & 8 & $8-9$ & 85 & $4-5$ \\
\hline Pete & 8 & $8-9$ & 81 & $9-8$ \\
\hline
\end{tabular}

${ }^{a}$ Isolate obtained from $\mathrm{X}$. Chen and race designation based on the U.S. standard set of differentials before 2010 (Chen et al. 2002).

b A dash (-) indicates a range of ITs with the predominant IT listed first across two repetitions of the experiment with two replications each.

c Averaged across two repetitions of the experiment with two replications each.

TABLE 7. Infection type (IT, 0 to 9 scale) on first and second leaves of seedlings and stripe rust intensity (percentage of leaf area diseased) and IT on flag leaves of differential wheat lines inoculated with Puccinia striiformis f. sp. tritici isolates AR13-06 and AR13-10 (both race PSTv-52a) that have adult-plant virulence pattern 5

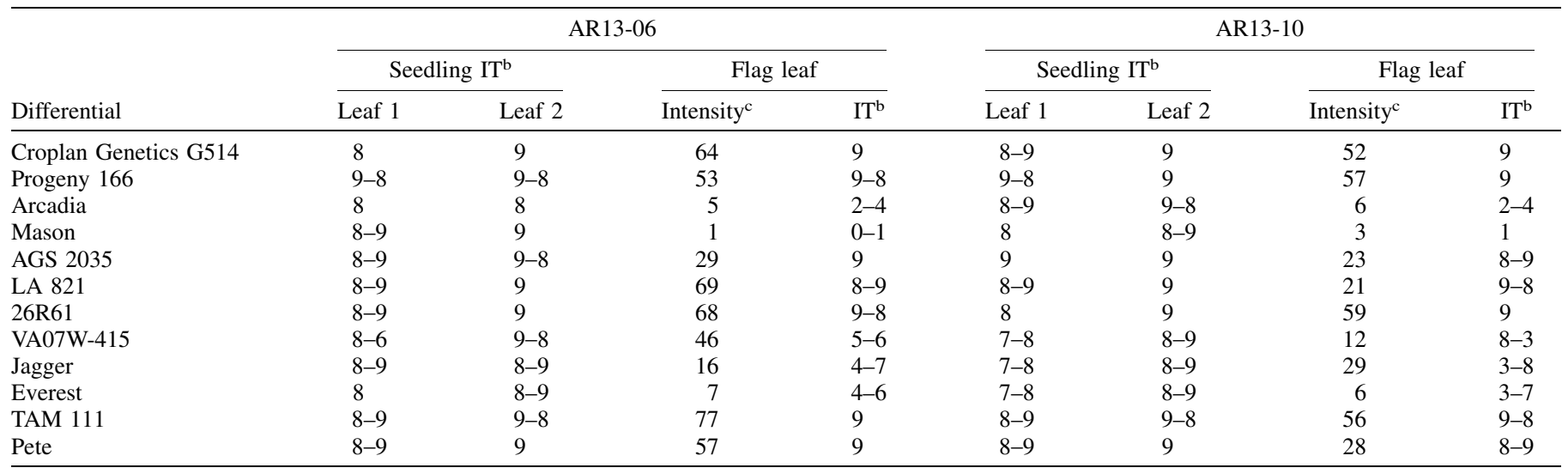

${ }^{a}$ Race designation based on the new U.S. standard set of differentials since 2010 (Chen 2014).

b A dash (-) indicates a range of ITs with the predominant IT listed first across two repetitions of the experiment with two replications each.

c Averaged across two repetitions of the experiment with two replications each. 

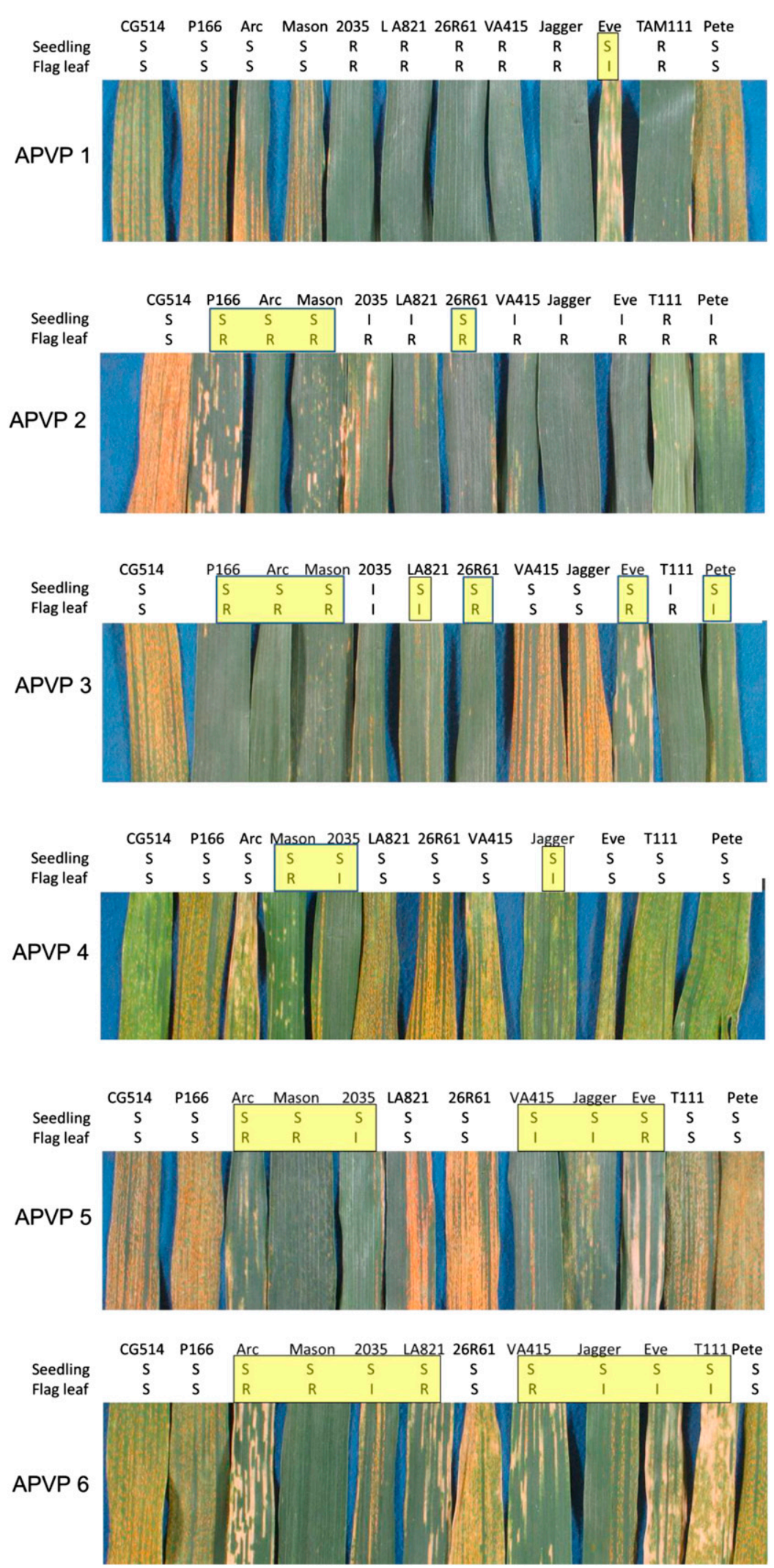

Fig. 1. Stripe rust infection on flag leaves of 12 winter wheat cultivars inoculated with isolates of Puccinia striiformis $\mathrm{f}$. sp. tritici representative of six adult-plant virulence patterns (APVP) and their reactions on seedlings $(S=$ susceptible $=$ infection type $[\mathrm{IT}] \geq 7$ on first and second leaves, $R=$ resistant $=$ IT $\leq 4$ on first and second leaves, I = intermediate $=$ IT 5 to 6 or resistant IT on first leaf and susceptible IT on second leaf) and flag leaves $(\mathrm{S}=\mathrm{IT} \geq 7$ and intensity similar to susceptible check, R = IT $\leq 4, \mathrm{I}=$ IT 5 to 6 or IT $\geq 7$ with intensity $<$ half that of susceptible check). CG514 = Croplan Genetics $514 \mathrm{~W}$ (susceptible check), P166 = Progeny 166, Arc $=$ Arcadia, Mason $=$ Mason, $2035=$ AGS 2035, LA $821=$ LA 821, 26R61 = 26R61, VA415 = VA07W-415, Jagger $=$ Jagger, Eve $=$ Everest, T111 $=$ TAM 111, Pete $=$ Pete. APVP $1=$ isolates AR90-01 and AR97-01 that are representative of the old P. striiformis f. sp. tritici strain that was present before 2000; APVP $2=$ isolates AR00-05 and AR03-33 of the new P. striiformis f. sp. tritici strain from 2000 and 2003, respectively; APVP $3=$ isolates AR10-04 and AR12-19 from 2010 and 2012, respectively; APVP 4 = AR12-25 from 2012; APVP 5 = isolates AR13-06 and AR13-10 from 2013; and APVP 6 = type isolate of race PST-127 from Washington State in 2007. Yellow shading around seedling and flag leaf reactions indicates race-specific adult-plant resistance. 
The all-stage resistance conferred by $\operatorname{Yr} 9$ in AGS 2035 and 26R61, by $\operatorname{Yr} 17$ in LA 821, VA07W-415 and Jagger, and by QYr.tam-2BL in TAM 111 were easy to identify when seedlings were inoculated with isolates AR90-01 or AR97-01 (both avirulent on $\operatorname{Yr} 9,17$ and $Q Y$ r.tam-2BL) because both seedling leaves had low or predominantly low ITs (Table 3). When inoculated with isolates AR00-05 or AR03-33 (both virulent on $Y r 9$ and avirulent on $\mathrm{Yr} 17$ ), the resistance conferred by $\operatorname{Yr} 17$ in the above three lines could be interpreted as either all-stage or adult-plant depending on which seedling leaf is considered to represent the seedling reaction (Table 4) and the IT threshold for distinguishing resistance from susceptibility as described previously by Milus et al. (2015). Likewise, AGS 2035 and TAM 111 had low to intermediate ITs on the first seedling leaf but mostly high ITs on the second seedling leaf when inoculated with AR10-04 or AR12-19 (Table 5). For these host-pathogen interactions, the IT on the first leaf was a more accurate predictor of the intensity and IT on flag leaves than the IT on the second leaf. As summarized in the companion paper (Milus et al. 2015), some stripe rust researchers consider the IT on the first leaf to represent the seedling reaction whereas other stripe rust researchers consider the IT on the second leaf to represent the seedling reaction. The results of this study support the use of the first leaf to represent the seedling reaction for wheat stripe rust as reported by Boshoff et al. (2002), Hubbard and Bayles (2013), Prashar et al. (2007), Yahyaoui et al. (2002), and Zadoks (1961) and are in in agreement with Stakman et al. (1962) who used the first leaf to evaluate seedling reactions for wheat stem rust and with Roelfs et al. (1992) who recommended that the first leaf be evaluated to determine seedling reactions for leaf, stem and stripe rusts of wheat. In addition to being a better predictor of the adult-plant reaction, utilizing reactions on the first leaf would shorten the time needed to conduct seedling tests for resistance and virulence. A quick completion of seedling tests was important in earlier times when tests were done in poorly designed greenhouses in which powdery mildew was a constant problem (A. P. Roelfs, personal communication).

Isolates AR00-05 and AR03-33 (APVP 2) of the new P. striiformis f. sp. tritici strain revealed a high level of APR in Progeny 166, Arcadia, Mason, Everest and Pete that were susceptible to isolates AR90-01 and AR97-01 (APVP 1) of the old strain. Virulence overcoming the resistance in Progeny 166, Arcadia, Everest and Pete evolved by 2012 (APVP 4), but the resistance in Mason has remained effective against all isolates tested. A similar phenomenon was reported recently from Europe (Sørensen et al. 2014). An isolate of the new P. striiformis f. sp. tritici strain $(P s t \mathrm{~S} 2)$ revealed high levels of APR in a cultivar and several recombinant inbred lines and near-isogenic lines with different QTL for APR that were susceptible to the old $P$. striiformis f. sp. tritici strain. Furthermore, a new race that was first detected in 2011 was virulent on several of the wheat lines that were resistant to PstS2. These examples indicate that $P$. striiformis f. sp. tritici isolates from different epidemiological regions can differ greatly in their ability to overcome race-specific APR.

Wheat breeders in the eastern United States have been concerned with incorporating stripe rust resistance into their cultivars only since the emergence of the new $P$. striiformis f. sp. tritici strain in 2000 (Basnet et al. 2014). As might be expected, the breeders' survey found high priorities for incorporating stripe rust resistance in the southern SRWW region and the southern and central HRWW regions that have experienced frequent stripe rust epidemics and low priorities in the northern SRWW and HRWW regions where stripe rust rarely becomes epidemic. The high priority among most HRWW breeders also may be due to few effective sources of resistance in adapted backgrounds. However, it is easier for SRWW breeders to develop resistant cultivars because there are many sources of effective resistance, as evidenced by the large number of highly resistant entries in the 2013 Arkansas Wheat Cultivar Performance Tests. The results of the survey also indicated that most of the current selection effort for stripe rust resistance is based on evaluations of adult plants in the field. However, breeders with a low priority for incorporating stripe rust resistance because epidemics are rare in their region tended to rely most on molecular markers for specific genes, whereas breeders with a high priority for incorporating stripe rust resistance because epidemics were common in their region tended to rely most on selection in the field. Although selection in the field can be effective for both allstage and adult plant resistances, our study found no evidence for currently effective all-stage resistance among the wheat lines evaluated. As of the 2013 season, $\operatorname{Yr} 5$ and 15 were the only all-stage genes in the U.S. set of stripe rust differentials that were resistant to all isolates evaluated for virulence (Chen 2014). However, virulence on $\operatorname{Yr} 5$ and 15 were reported from elsewhere more than 20 years ago before these genes were ever deployed in cultivars (McIntosh et al. 1995). Breeders listed $\operatorname{Yr} 5,10$, and 15 as the most frequently used all-stage resistance genes, but the probability for managing stripe rust in eastern United States with all-stage resistance seems to be low.

Unknown sources were most frequently used by both HRWW and SRWW breeders as sources of stripe rust resistance. Most of the adult-plant resistance described in this study is in this unknown category and appears to be responsible for protecting SRWW cultivars in southeastern United States and HRWW cultivars in the

TABLE 9. Summary of responses to survey questions by breeders of soft red winter wheat (SRWW) or hard red winter wheat (HRWW)

\begin{tabular}{|c|c|c|}
\hline \multirow[b]{2}{*}{ Survey question } & \multicolumn{2}{|c|}{ Breeder responses by wheat market class } \\
\hline & SRWW & HRWW \\
\hline \multicolumn{3}{|l|}{$\begin{array}{l}\text { Priority for incorporating stripe rust } \\
\text { resistance? }\end{array}$} \\
\hline High & 3 & 6 \\
\hline Moderate & 4 & 0 \\
\hline Low & 3 & 1 \\
\hline \multicolumn{3}{|l|}{ Percentage of selection effort is based on? } \\
\hline Seedling inoculations & Range 0 to $20 \%, \bar{X}=2 \%$ & Range 0 to $20 \%, \bar{X}=5 \%$ \\
\hline Adult plants in field & Range 0 to $100 \%, \bar{X}=67 \%$ & Range 65 to $90 \%, \bar{X}=82 \%$ \\
\hline Molecular markers & Range 0 to $100 \%, \bar{X}=31 \%$ & Range 9 to $35 \%, \bar{X}=13 \%$ \\
\hline \multicolumn{3}{|l|}{$\begin{array}{l}\text { Sources of stripe rust resistance by } \\
\text { percentage? }\end{array}$} \\
\hline Specific genes/markers & Range 0 to $100 \%, \overline{\mathrm{X}}=38 \%$ & Range 0 to $10 \%, \bar{X}=5 \%$ \\
\hline Specific lines/cultivars & Range 0 to $40 \%, \bar{X}=12 \%$ & Range 0 to $20 \%, \bar{X}=8 \%$ \\
\hline Unknown & Range 0 to $100 \%, \bar{X}=50 \%$ & Range 70 to $100 \%, \bar{X}=87 \%$ \\
\hline $\begin{array}{l}\text { Specific genes/markers being used? (number } \\
\text { of multiple responses in parentheses) }\end{array}$ & $\operatorname{Yr} 5,15,17(6), 18$ & $\operatorname{Yr} 5,10(2), 15,17,18,29,35,36(2), 38,42,45,52$ \\
\hline $\begin{array}{l}\text { Specific sources being used? (number of } \\
\text { multiple responses in parentheses) }\end{array}$ & $\begin{array}{l}\text { 26R61 (4), USG3555 (2), Jamestown, } \\
\text { VA00W-38, LA841 }\end{array}$ & TAM 111 (2), Duster, Billings, Fannin \\
\hline
\end{tabular}


Great Plains from stripe rust. Although this resistance appears to be race-specific and not durable, the resistance is highly effective against avirulent isolates. It also is found in diverse adapted backgrounds, easily selected in the field and likely to be simply inherited (Markell et al. 2009).

Some of the APR described in this study may be useful in other regions where stripe rust is a problem, and even susceptible cultivars from other regions may have additional race-specific APR genes that may be effective in the United States. International research efforts are needed to identify sources of race-specific APR and to survey regional $P$. striiformis f. sp. tritici populations for avirulence to the resistances. To prevent the introduction of exotic $P$. striiformis f. sp. tritici isolates, it would be best to exchange wheat lines rather than $P$. striiformis $\mathrm{f}$. sp. tritici isolates among regions.

\section{ACKNOWLEDGMENTS}

We thank the Arkansas Wheat Promotion Board and the Arkansas Agricultural Experiment Station for financial support; the Department of Plant Pathology for a graduate assistantship to K. Lee; X. Chen for race identifications based on all-stage resistance genes; P. S. Baenziger, B. Carver, C. Griffey, S. Harrison, J. Johnson, D. Marshall, R. E. Mason, J. Murche, P. Murphy, C. Sneller, M. Sorrells, J. Rudd, and five breeders who chose to remain anonymous for participating in the survey.

\section{LITERATURE CITED}

Basnet, B. R., Ibrahim, A. M. H., Chen, X., Singh, R. P., Mason, R. E., Bowden, R. L., Liu, S., Hays, D. B., Devkota, R. N., Subramanian, N. K., and Rudd, J. C. 2014. Molecular mapping of stripe rust resistance in hard red winter wheat TAM 111 adapted to the US High Plains. Crop Sci. 54:1361-1373.

Boshoff, W. H. P., Pretorius, Z. A., and van Niekerk, B. D. 2002. Establishment, distribution, and pathogenicity of Puccinia striiformis f. sp. tritici in South Africa. Plant Dis. 86:485-492.

Boyd, L. A. 2005. Can Robigus defeat an old enemy? - Yellow rust of wheat. J. Agric. Sci. 143:233-243.

Chen, X. M. 2005. Epidemiology and control of stripe rust [Puccinia striiformis f. sp. tritici] on wheat. Can. J. Plant Pathol. 27:314-337.

Chen, X. M. 2007. Challenges and solutions for stripe rust control in the United States. Aust. J. Agric. Res. 58:648-655.

Chen, X. M. 2014. Races of Puccinia striiformis f. sp. tritici in the United States in 2013. http://striperust.wsu.edu/races/stripe-rust-race-data.html

Chen, X. M., Moore, M., Milus, E. A., Long, D. L., Line, R. F., Marshall, D., and Jackson, L. 2002. Wheat stripe rust epidemics and races of Puccinia striiformis f. sp. tritici in the United States in 2000. Plant Dis. 86:39-46.

Cromey, M. G. 1992. Adult plant resistance to stripe rust (Puccinia striiformis) in some New Zealand wheat cultivars. N.Z. J. Crop Hortic. Sci. 20:413-419.

da Silva, A. R. 1958. The integration of wheat breeding and rust identification. Pages 39-48 in: Proceedings of the First International Wheat Genetics Symposium. Winnipeg, Manitoba, Canada.

Danial, D. L., Kirigwi, F. M., and Parlevliet, J. E. 1995. Lack of durability of resistance to cereal rusts in wheat when selection is for complete resistance. Plant Breed. 114:539-541.

Hao, Y., Chen, Z., Wang, Y., Bland, D., Buck, J., Brown-Guedira, G., and Johnson, J. 2011. Characterization of a major QTL for adult plant resistance to stripe rust in US soft red winter wheat. Theor. Appl. Genet. 123:1401-1411.

Hovmøller, M. S. 2007. Sources of seedling and adult plant resistance to Puccinia striiformis f. sp. tritici in European wheats. Plant Breed. 126:225-233.

Hubbard, A. J., and Bayles, R. A. 2013. UK cereal pathogen virulence survey, Yellow rust of wheat - 2012 annual report. NIAB, Cambridge, England.

Line, R. F. 2002. Stripe rust of wheat and barley in North America: A retrospective historical review. Annu. Rev. Phytopathol. 40:75-118.

Ma, H., and Singh, R. P. 1996. Expression of adult resistance to stripe rust at different growth stages of wheat. Plant Dis. 80:375-379.
Manners, J. G. 1950. Studies on the physiologic specialization of yellow rust (Puccinia glumarum (Schm.) Erikss. \& Henn.) in Great Britain. Ann. Appl. Biol. 37:187-214.

Markell, S. G., and Milus, E. A. 2008. Emergence of a novel population of Puccinia striiformis f. sp. tritici in eastern United States. Phytopathology 98:632-639.

Markell, S. G., Griffey, C. A., and Milus, E. A. 2009. Inheritance of resistance to stripe rust in three lines of soft red winter wheat. Crop Sci. 49:521-528.

Mason, R. E., Miller, R. G., Kelley, J. P., and Milus, E. A. 2013. Arkansas wheat cultivar performance tests 2012-2013. http://arkansasagnews.uark. edu/611.pdf

McIntosh, R. A. 2010. What do we mean by virulence? Is it time to move on from 1920? http://www.globalrust.org/sites/default/files/mcintosh_race.pdf

McIntosh, R. A., Wellings, C. R., and Park, R. F. 1995. Wheat Rusts: An Atlas of Resistance Genes. CSIRO, Australia.

Milus, E. A., Seyran, E., and McNew, R. 2006. Aggressiveness of Puccinia striiformis f. sp. tritici isolates in south-central United States. Plant Dis. 90: 847-852.

Milus, E. A., Kristensen, K., and Hovmøller, M. S. 2009. Evidence for increased aggressiveness in a recent widespread strain of Puccinia striiformis f. sp. tritici causing stripe rust of wheat. Phytopathology 99:89-94.

Milus, E. A., Lee, K. D., and Brown-Guedira, G. 2015. Characterization of stripe rust resistance in wheat lines with resistance gene $\operatorname{Yr} 17$ and implications for evaluating resistance and virulence. Phytopathology 105: 1123-1130.

Park, R. F., and Rees, R. G. 1989. Expression of adult plant resistance and its effect on the development of Puccinia striiformis f. sp. tritici in some Australian wheat cultivars. Plant Pathol. 38:200-208.

Prashar, M., Bhardwaj, S. C., Jain, S. K., and Datta, D. 2007. Phenotypic evolution in Puccinia striiformis in India during 1995-2004. Aust. J. Agric. Res. 58:602-604.

Priestley, R. H., and Doodson, J. K. 1976. Physiological specialization of Puccinia striiformis to adult plants of winter wheat cultivars in the United Kingdom. Pages 87-89 in: Proc. Fourth European and Mediterranean Cereal Rusts Conference. Interlaken, Switzerland.

Priestley, R. H., Bayles, R. A., and Thomas, J. E. 1984. Identification of specific resistances against Puccinia striiformis (yellow rust) in winter wheat varieties. I. Establishment of a set of type varieties for adult plant tests. J. Natl. Inst. Agric. Bot. 16:469-476.

Qayoum, A., and Line, R. F. 1985. High-temperature, adult-plant resistance to stripe rust of wheat. Phytopathology 75:1121-1125.

Roelfs, A. P. 1984. Race-specificity and methods of study. Pages 131-164 in: The Cereal Rusts, Volume 1. Origins, Specificity, Structure, and Physiology. W. R. Bushnell and A. P. Roelfs, eds. Academic Press, New York.

Roelfs, A. P., Singh, R. P., and Saari, E. E. 1992. Rust Diseases of Wheat: Concepts and Methods of Disease Management. CIMMYT, D.F., Mexico.

Sørensen, C. K., Hovmøller, M. S., Leconte, M., Dedryver, F., and de Vallavieille-Pope, C. 2014. New races of Puccinia striiformis found in Europe reveal race-specificity of long-term effective adult plant resistance in wheat. Phytopathology 104:1042-1051.

Stakman, E. C., Stewart, D. M., and Loegering, W. Q. 1962. Identification of physiologic races of Puccinia graminis var. tritici. United States Department of Agriculture, Agricultural Research Service E617.

Sthapit, J., Gbur, E. E., Brown-Guedira, G., Marshall, D. S., and Milus, E. A. 2012. Characterization of resistance to stripe rust in contemporary cultivars and lines of winter wheat from the eastern United States. Plant Dis. 96: $737-745$.

Vanderplank, J. E. 1982. Host-Pathogen Interactions in Plant Disease. Academic Press, London.

Wan, A., and Chen, X. 2012. Virulence, frequency, and distribution of races of Puccinia striiformis f. sp. tritici and P. striiformis f. sp. hordei in the United States in 2008 and 2009. Plant Dis. 96:67-74.

Yahyaoui, A. H., Hakim, M. S., El Naimi, M., and Rbeiz, N. 2002. Evolution of physiologic races and virulence of Puccinia striiformis on wheat in Syria and Lebanon. Plant Dis. 86:499-504.

Zadoks, J. C. 1961. Yellow rust on wheat, studies in epidemiology and physiologic specialization. Tijdschr. Plantenziekten 67:69-256. 